\title{
IMPACT OF COVID-19 LOCKDOWN ON NO2, NOx, O3 AND PM2,5 CONCENTRATIONS IN SANTIAGO DE CHILE
}

\author{
SONNIA PARRA AND MANUEL A. BRAVO*
}

Laboratorio de Química Analítica y Ambiental, Instituto de Química, Pontificia Universidad Católica de Valparaíso, Avenida Brasil 2950, Valparaíso, Chile.

\begin{abstract}
Based on the spread of the COVID-2019, a lockdown was declared in the Santiago Metropolitan area in Chile.

The application of containment measures allowed to reduce the impact of the COVID-2019 pandemic on the National Health System (MINSAL) but at the same time these restriction measures gave also the opportunity to assess the effect of anthropogenic activities on air pollutants.

A comparative study of typical behavior of atmospheric pollutants $\mathrm{O}_{3}, \mathrm{NO}_{2}, \mathrm{NO}_{\mathrm{x}}$ and $\mathrm{PM}_{2.5}$ during the years 2015-2020 are presented.

For the eight studied stations (Las Condes, Pudahuel, El Bosque, Cerro Navia, La Florida, Independencia, Parque O`Higgins and Puente Alto) it was possible to determine the seasonal variation of $\mathrm{NO}_{2}, \mathrm{NOx}, \mathrm{O}_{3}$ and $\mathrm{PM}_{2.5}$.

As results of impact of the lockdown, in this paper we have been determined a significant reduction of pollutants concentration mainly due to vehicular traffic.
\end{abstract}

Keywords: Coronavirus COVID-19; Atmospheric contamination; Santiago-Chile.

\section{INTRODUCTION}

After the detection of the first case of the coronavirus (Covid-19) on March 3 of 2020, Chilean authorities declare catastrophe status for 90 days from 18 March [1], for preventing the spread of pandemic and preserving the health and safety of the population. This status considers restriction of free movement, suspension of classes, quarantines, closure of all borders, maritime, land and air of the country, as well as closure of commercial activities and reduction of industrial activities [2,3]. In this way, the sector with more contagious and more extensive quarantine period is the Santiago metropolitan area, especially in the communes of the eastern sector such as Las Condes, Providencia and Ñuñoa [3,4].

In this context, several studies from different countries have reported that the reduction of anthropogenic activities, during Covid-19 outbreak, has played a significant role in air pollution decrease and could influence the total ambient air quality. Such is the case of Berman and Ebisu, (U.S) [5]; Kondo and Custodio, (Brazil) [6]; Tobias et al., (Spain) [7]; who reported $\mathrm{NO}_{2}$ and $\mathrm{PM}_{2.5}$ declines statistically significant during the COVID-19 pandemic, due to vehicular traffic decrease.

Otnami et al., (North-Western Morocco) [8], also found changes in levels of air pollutants $\mathrm{PM}_{10}(75 \%), \mathrm{NO}_{2}(96 \%)$ and $\mathrm{SO}_{2}(49 \%)$ during the Covid-19 lockdown period, associated to reducing industrial and vehicular traffic.

Farhan et al., [9], found that environmental pollutants such as $\mathrm{PM}_{10}, \mathrm{PM}_{25}$, $\mathrm{SO}_{2}, \mathrm{NO}_{2}$, and $\mathrm{CO}$ have a significant correlation with the COVID-19 epidemic in California, , associated to reducing industrial and vehicular traffic. Equally, Hudda et al., [10] found significant changes in traffic-related air pollutant concentrations in an urban area from USA during the COVID-19 pandemic. Sharma et al., [11] also analyzed local data from different regions in India. The authors observed $43 \%$ and $31 \%$ reduction of particulate matter $\left(\mathrm{PM}_{2.5}\right)$ and particulate matter $\left(\mathrm{PM}_{10}\right)$, respectively, during the lockdown compared to the same time period of the past four years.

In the case of Chile, there is only one study where it has been evaluated the impact of the lockdown strategies adopted during the COVID-19 pandemic on the air quality of the Santiago Metropolitan Area [12].

However, to date no studies have reported on changes in air quality due to the sharp decreases in roadway traffic, and in industrial activities, following the COVID-19 outbreak in different zones of Santiago Metropolitan Area during the years 2015-2020.

In this way, the objective of the present paper is to assess the variations of $\mathrm{PM}_{2.5}, \mathrm{NOx}, \mathrm{NO}_{2}$ and $\mathrm{O}_{3}$ concentrations in the air of different zones of Santiago Metropolitan Area (Las Condes, Pudahuel, El Bosque, Cerro Navia, Florida, Independencia, Parque O'Higgins and Puente Alto) before and during the propagation of Covid-19 pandemic. Furthermore, we investigated typical behavior of atmospheric pollutants in Santiago to understand the dynamics of atmospheric pollutants since the different processes of formation.

\section{MATERIALS AND METHODS}

\subsection{Study area}

In 2014, the Organization for Economic Cooperation and Development (OECD) ranked Chile as the country with the highest air pollution among its 36 members. Furthermore, Santiago Metropolitan Area is the largest urban area in Chile where $41 \%$ of the country's population resides, is ranked as the city with the fourth worst air quality on the continent $[13,14]$.

Santiago city is located in the Maipo and Mapocho rivers valley and surrounded by the Los Andes Mountains to the east and ends in a series of mountain ranges to the north, south and west [15]. This mountainous environment do not allow air ventilation and cause high level of pollution in the region, especially in the winter months [16]. For these reasons, the air quality is permanently monitored and several "Pre-emergency" (level for $\mathrm{PM}_{2.5}$ between $110-169 \mu \mathrm{g} / \mathrm{m} 3$ ) [17]; air pollution alerts can be declared when air quality is detrimental to the health of the population.

In this study, the hourly average of $\mathrm{PM}_{2.5}, \mathrm{NOx}, \mathrm{NO}_{2}$ and $\mathrm{O}_{3}$ concentrations were collected from January 2015 to July 2020, from 8 sites placed in Santiago de Chile (Las Condes, Pudahuel, El Bosque, Cerro Navia, La Florida, Independencia, Parque O`Higgins and Puente Alto). The data were downloaded by the Sistema de Informacion Nacional de Calidad del Aire (SINCA). Spatial locations of the monitoring stations are described in Figure 1.

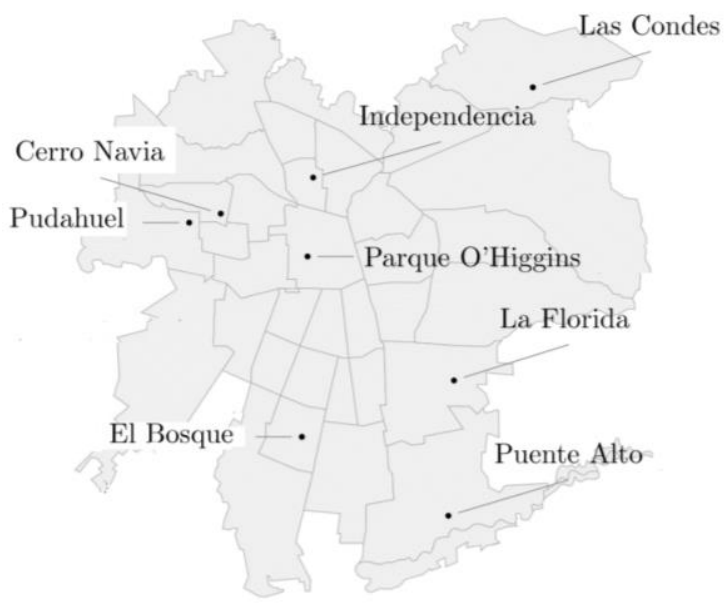

Figure 1. location of the measurement sites (01 January 2015 to 05 July 2020) in Santiago Metropolitan Area.

In this study, the study sites show different characteristics that mainly depend on the density of the population, and directly affected by traffic emissions. 
For example, the Pudahuel monitoring station is located in the commune with the largest geographical area, with a land surface of $197.4 \mathrm{~km}^{2}$. In addition, it is one of the country's most polluted communes in terms of average $\mathrm{PM}_{2.5}$ concentrations [17]. On the other hand, Cerro Navia, is the station exhibits the worst contamination rates, due mainly to the combined high consumption of firewood and high population density in this commune [17].

Equally, La Florida and El Bosque are located in the southern part of Santiago. Both stations they have traffic influence due to their location close to large streets. In the case of Parque O'Higgins, this is a station where it exists a mixture of houses, retail and small companies [18].

Las Condes is located in the eastern part of Santiago at an altitude of $700 \mathrm{~m}$ above sea level. This city is located near an avenue where about 15,000 vehicles circulate daily. The area is primarily residential, with some retail stores located around the larger streets [18]. In this year, Las Condes presented the highest number of confirmed cases (181 patients) of COVID-19 in the Country and the place with one of the most extensive quarantine period [2, 4].

\subsection{Dataset}

Hourly $\mathrm{O}_{3}, \mathrm{NO}_{2}, \mathrm{NO}_{\mathrm{x}}$ and $\mathrm{PM}_{2.5}$ were measured from 01 January 2015 to 05 July 2020 in selected locations. The generated database with all these atmospheric parameters measured during these five years was compiled in the National Air Quality Information System (SINCA) of the Ministry of the Environment of Chilean government and transferred to MATLAB for statistical analysis. This database has the experimental data stored every hour of every day during every year, giving a long data vector sized $(1 \times 8760)$ per year. A total number of 40 data vectors of this size, one per year of the five considered (20152020) and one for every one of the eight monitoring stations, Las Condes, Pudahuel, El Bosque, Cerro Navia, Florida, Independencia, Parque O’Higgins and Puente Alto.

Each hourly $\mathrm{O}_{3}, \mathrm{NO}_{\mathrm{x}}, \mathrm{NO}_{2}$ and $\mathrm{PM}_{2.5}$ concentrations considered between 01 January and 31 December 2019 were stored in a hourly-year matrix form $((365 \times 24) \times 5)$ and the mean hourly data were calculated. Then, the data were subjected to Whittaker smoother was used for offset correction and to smooth (lambda $=100 ; d=2$ ) on every concentration data [19] . To make all these data have the same size, the extra days of 2016 and 2020 (leap-years) were removed. Occasional day missing $\mathrm{O}_{3}, \mathrm{NO}_{\mathrm{x}}$ and $\mathrm{NO}_{2}$ concentration data (lower than $10 \%$ for all stations) were replaced by the mean of all the values in the same column of the data matrix.

\section{RESULTS}

\subsection{Typical behavior of atmospheric pollutants in Santiago}

Study of hourly cycles of $\mathrm{O}_{3}, \mathrm{NO}_{2}$, NOx and $\mathrm{PM}_{2.5}$ are important to understand the dynamics of atmospheric pollutants since the different processes of formation. The annual variations observed in the different cycles of atmospheric pollutants during the years 2015-2020 are presented in Fig. 2. As can be seen, the $\mathrm{NO}_{2}, \mathrm{NOx}$ and $\mathrm{PM}_{2.5}$ cycles exhibited a like pattern with one peak major appearing in the months of June and July, corresponding to the winter months in Chile. Particularly, the peak of $\mathrm{PM}_{2.5}$, similar to $\mathrm{NO}_{2}$, can be attributed to emission of large amount of pollutants from vehicular sources [20].
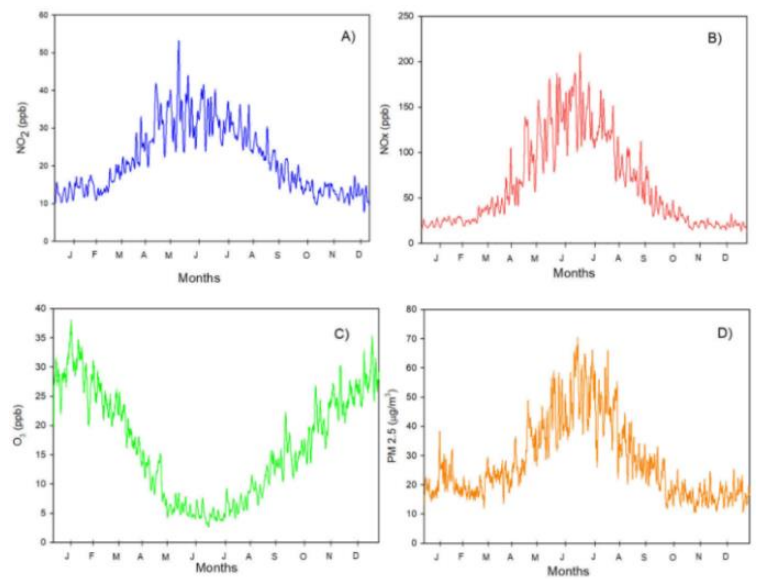

Figure 2. Annual variations in the $\mathrm{NO}_{2}, \mathrm{NOx}, \mathrm{PM}_{25}$ and $\mathrm{O}_{3}$ levels during 2015-2020.
Contrarily, the annual cycle of $\mathrm{O}_{3}$ shows one distinct peak, showing a significant decreasing during the winter months. This fact may be explained because the ozone concentrations are influenced by meteorology in many ways. Various studies have shown that ozone concentrations increase with radiation and temperature elevation [21]. Besides, the gradual increase in the ozone levels in the summer month, may be attributed to the prevalence of photochemical processes in the atmosphere producing ozone with enhancing intensity of the solar radiations. This fact it is because the highest concentrations of troposphere ozone occur in the periods in which the incident solar radiation is greater, that is, the warmer seasons and times of greater sunlight [22].In fact, during the summer months, central Chile is generally under the influence of the sub-tropic anticyclone in the south-eastern pacific, resulting in clear sky and high temperatures in Santiago, conditions under which ozone formation is favored $[23,24,25]$

3.2 Seasonal variations of $\mathrm{NO}_{2}, \mathrm{NO}_{X}, \mathrm{PM}_{2.5}$ and $\mathrm{O}_{3}$ of different zones of Santiago metropolitan

The seasonal variation of $\mathrm{NO}_{2}, \mathrm{NOx}, \mathrm{O}_{3}$ and $\mathrm{PM}_{2.5}$ for the eight studied stations (Table 1) is shown in Figure 3a- 3d.
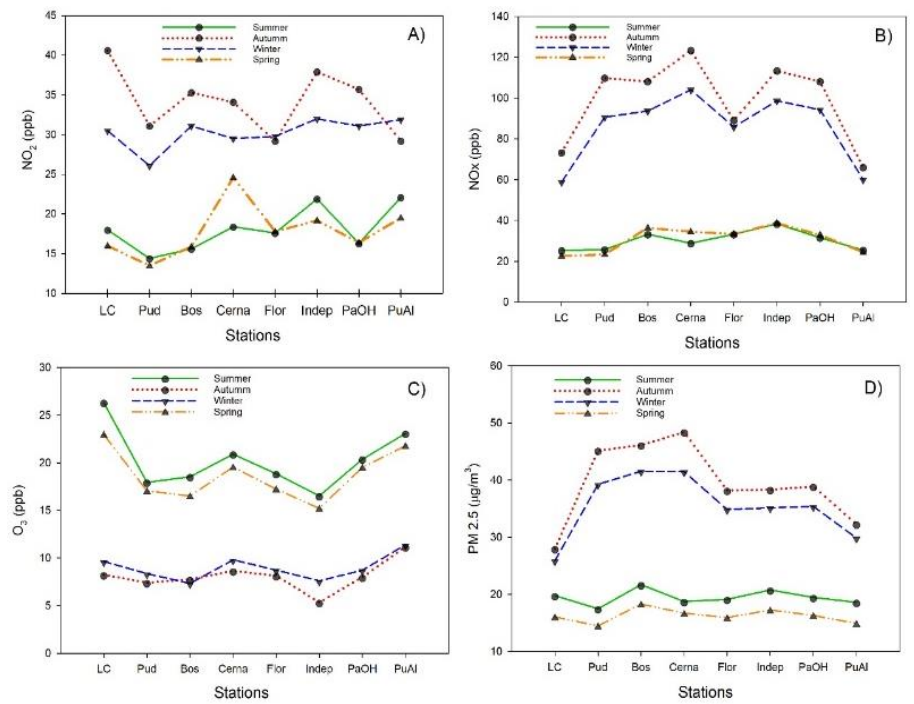

Figure 3. Seasonal variations of (a) $\mathrm{NO}_{2}$, (b) $\mathrm{NO}_{\mathrm{X}}$, (c) $\mathrm{O}_{3}$, and (d) $\mathrm{PM}_{2.5}$.

According to this variation were observed similar seasonal trends for the data of $\mathrm{NOx}, \mathrm{NO}_{2}$ and $\mathrm{PM}_{2.5}$ during the months of autumn and winter (colder periods of the year). During these months there is a certain prevalence of thermal inversions near the surface and weak winds, where pollutants tend to accumulate due to meteorological conditions not favorable to dispersion thus causing high pollutant concentrations [26].

As seen in figure $3 \mathrm{a}$, and $3 \mathrm{~b}$, in the month's summer and spring, the higher levels of solar radiation and temperature favour photochemical reactions decreasing the $\mathrm{NO}_{2}$ and $\mathrm{NO}_{\mathrm{X}}$ levels. Additionally, in the case of $\mathrm{NO}_{2}$ and $\mathrm{NO}_{\mathrm{X}}$, the higher levels they showed up at the station Las Condes, suggesting a strong influence of mobile sources, where NO is mainly emitted by vehicle exhausts.

Equally, the variations in $\mathrm{NO}_{2}$ concentration levels may be due to the temperature variations associated to different seasons. On the other hand, the figure 3c, shows that the $\mathrm{O}_{3}$ exhibited higher concentrations during summer; while, the minimum concentration levels were found in the winter season. This tendency suggests that in summer and spring, sun inclination is smaller, the temperature is higher and longer days increase photochemistry, thus resulting in high $\mathrm{O}_{3}$ concentrations [22].

As seen in Figure 3d, the Cerro Navia station presents a high concentration of $\mathrm{PM}_{2.5}$ in autumn and winter, which coincides with studies by Moisan et al., 2018 [17] where this station presented a high hourly average $\mathrm{PM}_{2.5}$ over the period 2011-2015 of $29.45 \mu \mathrm{g} / \mathrm{m}^{3}$. Therefore, the high levels of $\mathrm{PM}_{2.5}$ could be attributed to the fact that this station exhibits the worst pollution indices, mainly due to the high consumption of firewood in the coldest months of the year. 
On the other hand, in the Las Condes station lower the levels of $\mathrm{PM}_{2.5}$ (Figure 3d) are observed. This could be explained because Las Condes is located at a higher altitude than other communes, and thus has the benefit of better atmospheric ventilation.

\subsection{COVID-19 Effect on air pollutants}

Several studies have reported that reducing anthropogenic activities during Covid-19 outbreak plays a significant role in air pollution [27, 8].

$\mathrm{PM}_{2.5}$, and $\mathrm{NO}_{2}$ are very common ambient air pollutants in urban environments e.g Santiago Metropolitan Area, and various studies carried out have demonstrated their

severe health related problems like respiratory a lung cancer. $\mathrm{NO}_{2}$ can also react with other atmospheric chemicals to form $\mathrm{O}_{3}$, which is another important gas pollutant and also harmful to the respiratory system [28]

In this study the comparison of the $\mathrm{NO}_{2}$ concentration in Las Condes prior (2015-2019) and during the quarantine period (2020) showed a substantial difference.

This variation of urban $\mathrm{NO}_{2}$ is attributable to the significant reduction in vehicular traffic given by the restrictions imposed by the Authorities (Figure 4). $\mathrm{NO}_{2}$ is emitted from combustion processes, mostly road traffic (e.g., motor exhaust; brake, wear and road erosion) in urban areas, especially diesel and, to a lesser extent, gasoline, vehicles, among others [29].

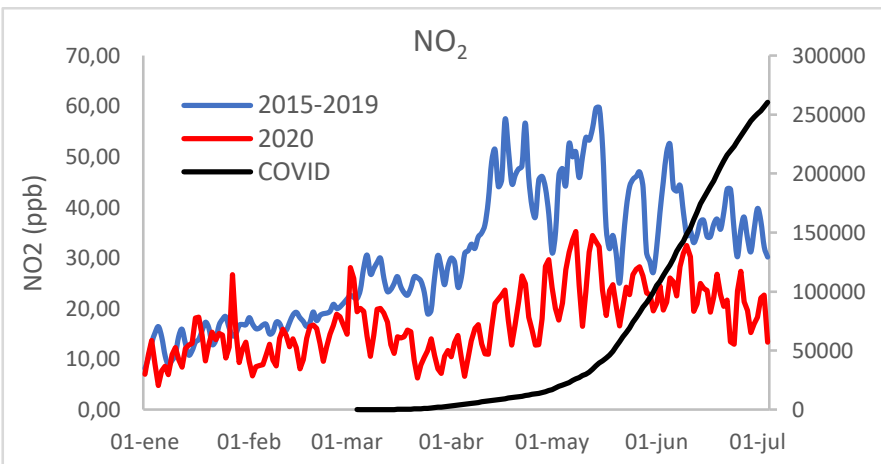

Figure 4. Variation daily average of $\mathrm{NO}_{2}$, in relation with COVID-19 in Las Condes over January-July 2020.

The reduction of $\mathrm{NO}_{2}$ recorded in this study agree with the results obtained in the lockdown period imposed by CoViD-19 in Barcelona (7), Italy [30] and confirmed by Copernicus satellite system which highlighted the substantial reduction of tropospheric $\mathrm{NO}_{2}$ in Milan [31].

Equally, as shown in Figure 5, the levels of $\mathrm{O}_{3}$ markedly increased in Las Condes during the quarantine period (2020) as a consequence of the NOx emissions reduction [32]. These results are consistent with the recent findings in Italy, Zoran et al., [30]; In China, Wang et al., [33], among others.

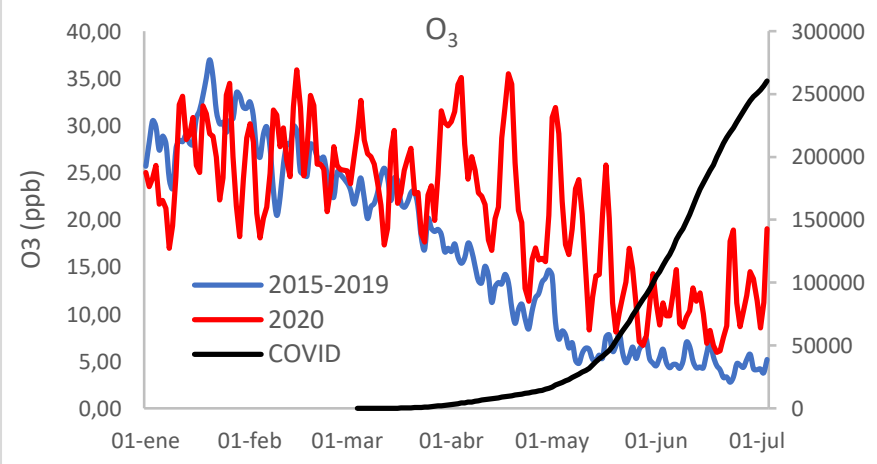

Figure 5. Variation daily average of $\mathrm{O}_{3}$, in relation with COVID-19 in Las Condes over January-July 2020,

\section{CONCLUSIONS}

The lockdown measures implemented in the Santiago Metropolitan Area by the Chilean government in response to the COVID-19 pandemic affected the industry, transportation and other human activities in early 2020.

In this paper the effect of this lockdown on air quality in Santiago Metropolitan Area was assessed. The comparison of the $\mathrm{NO}_{2}$ concentration in Las Condes prior (2015-2019) and during the quarantine period (2020) showed a substantial difference. This variation of urban $\mathrm{NO}_{2}$ is attributable to the significant reduction in vehicular traffic given by the restrictions imposed by the Authorities. On the other hand, despite the significant decrease in $\mathrm{NO}_{2}$, ozone exhibited a significant increase, probably related to the changes in $\mathrm{NO}_{2}$.

\section{ACKNOWLEDGEMENTS}

The authors acknowledge to the Dirección de Investigación y Estudios Avanzados (VRIEA-PUCV) for financial support (Proyecto VRIEA-PUCV 039.470/2020).

\section{REFERENCES}

1. BBC. Coronavirus: Chile decreta el "estado de catástrofe," (2020).

2. Minsal. Informe Epidimiologico Enfermedad por COVID-19, (2020).

3. Ciampi. E, Uribe. R, Cárcamo, C. Multiple Sclerosis and Related Disorders, 42, 102204, (2020)

4. Minsal. Plan de acciòn coronavirus Covid-19. www.minsal.cl, (2020)

5. Berman. JD, Ebisu. K. Sci Total Environ, 739,139864, (2020)

6. Kondo. L, Custodio. R. Science of the Total Environment, 73,:139087, (2020)

7. Tobías. A, Carnerero. C, Reche. C, Massagué. J, Viana. M, Minguillón. C, et al. Sci Total Environ, 726:138540, (2020).

8. Otmani. A, Benchrif. A, Tahri. M, Bounakhla. M, Mahjoub. E, et al. Sci Total Environ, 735,2,139541, (2020).

9. Farhan. M, Jiang. B, Komal. B, Adnan. M, Hassan. T, Iqbal. N, et al. Environ Res, 187,109652, (2020)

10. Hudda. N, Simon. MC, Patton. AP, Durant. JL. Sci Total Environ, 742 140931, (2020).

11. Sharma. S, Zhang. M, Gao. J, Zhang. H, Harsha. dSci Total Environ, 728 138878, (2020)

12. Toro. R, Catalàn. F, Urdanivia. F, Rojas. J, Manzano C, Seguel. R. Urban Clim, 36, (2021)

13. WHO. Urban outdoor air pollution database. Tech. rep. Department of Public Health and Environment, (2011).

14. INE. Demographic data (in Spanish) instituto nacional de Estadísticas, Santiago, (2017)

15. Toro. R, Kvaki. M, Klaic. Z, Koracin. D. Environmental Pollution, 244,705-714, (2019).

16. Nuñez. L, Jordanova. P, Nicolis. O, Stehlík. Chemometrics and Intelligent Laboratory Systems, 12, 73-84, (2019).

17. Moisan. S, Herrera. R, Clements. A. International Journal of Forecasting, $34,4,566-581,(2018)$.

18. Gramsch. E, Cereceda. F, Oyola. P, Baer. D. Atmospheric Environ. 40, 5465-5475 (2006)

19. Eilers. PHC. Anal. Chem, 75, 3631-3636, (2003).

20. Prieto. L, Yohannessen. K, Brea. C, Vidal. D, Ubilla. CA, Ruiz. P. Environment International, 101,190-200, (2017)

21. Pudasainee. D, Sapkota. B, Lal. M. Atmospheric Environment, 40, 80818087, (2006)

22. Calesso. E, Ramos. E, Santana. D, Wiegand .F, Fachel. J. Atmos. Environ, 43, 2213-2220, (2009)

23. Rubio. MA, Oyola. P, Gramsch. E, Lissi. E, Pizarro. J, Villena. G. Atmos Environ, 38, 4931-4939, (2004).

24. Schmitz. R. Atmos. Environ, 39, 2035-2047, (2005).

25. Rappengluck. B, Schmitz. R, Bauerfeind. M, Cereceda.F, Baer, Jorquera, H et al. Atmos. Environ, 39, 2913-2931, (2005).

26. Jorquera. H. Atmos. Environ, 36, 315-330, (2002).

27. He. G, Pan. Y, Tanaka. Nature Sustainability, 3, 1005-1011, (2020).

28. Li. J, Nagashima. T, Kong. L, Ge. B, Yamaji. K, Fu. JS, et al. Atmos. Chem. Phys., 19, 12993-13015, (2019).

29. Lee. D, Holland.R, Falla. N. Atmos. Environ. 30, 1053-1065, (1996).

30. Zoran. MA, Savastru. RS, Savastru. DM, Tautan. MN. Sci. Total Environ 740, 140005, (2020).

31. ESA. Coronavirus Lockdown Leading to Drop in Pollution across Europe Eur. Sp. Agency, (2020).

32. Monks. PS, Archibald. AT, Colette. A, Cooper. O, Coyle. M, Derwent. R, et al Atmos. Chem. Phys., 15, 8889-8973, (2015).

33. Wang. P, Chen. K, Zhu. S, Wang. P, Zhang. H. Resour. Conserv. Recycl. 158 , 104814, (2020) 